\title{
Pressure and protective factors influencing nursing students' self-esteem: A content analysis study
}

\author{
Leila Valizadeh ${ }^{\text {a }}$, Vahid Zamanzadeh ${ }^{\mathrm{b}}$, Rahim Badri Gargari ${ }^{\mathrm{c}}$, Akram Ghahramanian $^{\mathrm{b}}$, \\ Faranak Jabbarzadeh Tabrizi $^{\text {b,* }}{ }^{\text {, Brian Keogh }}{ }^{\text {d }}$ \\ a Department of Pediatric nursing, Faculty of Nursing and Midwifery, Tabriz University of Medical Sciences, Tabriz, Iran \\ b Department of Medical Surgical Nursing, Faculty of Nursing and Midwifery, Tabriz University of Medical Sciences, Tabriz, Iran \\ c Department of Psychology, University of Tabriz, Tabriz, Iran \\ d School of Nursing \& Midwifery, Trinity College Dublin, Dublin, Ireland
}

\section{A R T I C L E I N F O}

Article history:

Accepted 20 October 2015

\section{Keywords:}

Nursing student

Self-esteem

Qualitative research

Nursing

\section{S U M M A R Y}

Background: A review of the literature shows that the range of self-esteem in nursing students ranges from normal to low. It is hypothesized that different contextual factors could affect levels of self-esteem.

Objective: The main aim of this study was to explore these factors from the viewpoint of Iranian nursing students using a qualitative approach.

Design: A qualitative content analysis study.

Setting: Faculty of Nursing and Midwifery, 2014.

Participants: Fourteen student nurses and two qualified nurses.

Methods: This study has been applied to various depths of interpretation. Semi-structured interviews were used to collect the data. Fourteen student nurses and two qualified nurses were interviewed.

Results: Two main themes of the "pressure factors" with subthemes: low self-efficacy, sense of triviality, ineffective instructor-student interaction, low self-confidence and "protective factors" with subthemes: knowledge acquisition, mirror of valuability, professional autonomy, religious beliefs, and choosing the nursing field with interest was extracted in this study. Results showed that these themes have interaction with each other like a seesaw, as pressure factors decrease, the effect of protective factors on the self-esteem are increased.

Conclusion: Nurse educators not only should try to improve the students' skills and knowledge, but should also try to enhance the protective factors and decrease pressure factors by enhancing the nursing students' feeling of being important, using participatory teaching methods, considering students' feedback, and attempting to improve facilities at the clinics are also recommended.

(C) 2015 Published by Elsevier Ltd.

\section{Introduction}

As early as 1890, William James pointed out that people form an idea of their own individual characteristics (for example, their needs, abilities, etc.) and therefore they gain an impression of their own character. This impression is described as the person's self-concept and this selfconcept is not limited to a description of the individual, but rather an evaluation which is described as self-esteem (Kanning and Hill, 2012).

In general, low self-esteem has been linked with depression (King et al., 1993), anxiety (Rosenberg, 1986), and is associated with poor mental health, self-efficacy, body image, and sense of leadership (Ni et al., 2010). Nursing students have a great responsibility in the future in terms of the role they play as health care providers (Cha and Sok,

\footnotetext{
* Corresponding author at: Department of Medical Surgical Nursing, Faculty of Nursing and Midwifery, Phd Candidate of Nursing, Tabriz University of Medical Sciences, Tabriz, Iran. Tel./fax: + 984134770648 .

E-mail address: jabbarzadehf@tbzmed.ac.ir (F.J. Tabrizi).
}

2014). It can be argued that the presence of negative feelings in nursing students will result in far more negative consequences than students of other disciplines (Megahed and Mohammad, 2014).Therefore, it can be hypothesized that nursing students need to have a high level of self-esteem (Megahed and Mohammad, 2014). Unfortunately, this does not appear to be the case as many studies identify that low self-esteem among nursing students is prevalent (Barkhordary et al., 2009; Dimitriadou-Panteka and Koukourikos, 2014; Megahed and Mohammad, 2014). There are some studies, however, which suggest a normal or medium range or rising trend of nursing students' selfesteem during their education (Suliman and Halabi, 2007; Furegato et al., 2008; Janati et al., 2012). It is hypothesized that different contextual factors could be affecting the diversity of levels of self-esteem. Based on this hypothesis, we decided to further explore self-esteem among nursing students using the research question: "What are the factors that affect levels of self-esteem among nursing students?"

A review of the literature demonstrated that most studies which focused on the factors affecting students' self-esteem were done using 
correlation methods (Suliman and Halabi, 2007; Barkhordary et al., 2009; Kamali et al., 2009; Ni et al., 2010; Janati et al., 2012; Peyrovi et al., 2012; Azizi et al., 2013; Iacobucci et al., 2013; Tameh et al., 2014).

These studies suggest that the low self-esteem of student nurses significantly correlate with student's attrition rate and depression (Azizi et al., 2013; Peterson-Graziose et al., 2013). In addition, these studies argue that some teaching strategies and interpersonal relationship educational programs could promote self-esteem levels and that levels of self-esteem rose as students neared the end of their course (Lo, 2002; Begley and White, 2003; Yoon et al., 2011; Ni et al., 2012; Lakdizaji et al., 2013). However, no study could be located which specifically focused on exploring the factors affecting self-esteem from the viewpoints of nursing students. Therefore, the main aim of this study was to explore factors affecting self-esteem among Iranian nursing students using a qualitative approach.

\section{Material and Methods}

\section{Participants and Setting}

In order to explore students' experiences, a qualitative content analysis approach was used. Participants (14 nursing students and 2 newly graduated nurses) were chosen based on purposive sampling and saturation principles. The inclusion criteria included studying as a nursing undergraduate student in faculties affiliated to Tabriz University of Medical Sciences (Tabriz and Maragheh branch) or Islamic Azad University (Tabriz and Bonab branch) in the North West of Iran. The School of Nursing and Midwifery in Tabriz has a nearly 100-year history in educating nursing students and currently provides nursing education at undergraduate and postgraduate levels. In addition to the state universities in Iran, nursing education is also provided by the non-state sector which is known as the Islamic Azad University; however, both universities have the similar curricula. Two newly qualified nurses were also interviewed and while their data were not included in the final analysis, it was used to support and confirm the themes which emerged from the student interviews.

\section{Data Collection}

Semi-structured interviews were used to collect the data. In addition, nursing students were observed in their natural environment. This meant that students' care behaviors were observed at the patient's bedside, in the classroom, and in their interactions with other students and teachers. Field notes were used to record these observations in the natural environment.

Data were collected from September until the end of January 2014 Interviews were conducted in a place of convenience for the participants and each interview lasted about 45 minutes and began with general informal questions. However, the questions became more detailed as the simultaneous processes of data collection and analysis progressed. Interviews began with a general question, for example, "As a nursing student, when you hear the term 'self-esteem' what comes to your mind?" Or "Based on your experiences, what factors influence self-esteem in nursing students?" Some participants, were interviewed twice in order to improve the depth of data collection and to reach saturation in the emergent categories and subcategories. Maximum variation in sampling was considered with the participants' gender, age, entrance year, and the participant's academic progress.

\section{Data Analysis}

The interviews were recorded and transcribed verbatim by the researchers. The transcripts and field notes were read repeatedly in order to obtain a full understanding of the data. Whole interviews and field notes were considered as units of analysis. Words, sentences, and paragraphs considered as units of meaning were condensed according to their content and context. The condensed meaning units were abstracted and labeled with codes. Codes were sorted into subcategories and categories based on comparisons regarding their similarities and differences. Discussion about the process of coding and categorizing the data frequently continued with all of the researchers involved until consensus was achieved.

In this study, we obtained two main categories and nine subcategories. To increase the validity of the data, the codes were compared, and the differences were discussed and re-evaluated in group research until shared codes and categories were created. Throughout the entire analytic process, subcategories and categories were compared with the original texts until consensus among all authors was attained.

Credibility and conformability were established through member checking. The report of the analyses was returned to the participants in order to get assurance that the researchers had portrayed their real world in codes and extracted categories (Rolfe, 2006).

\section{Ethical Considerations}

Ethical approval was achieved from ethical committee of Tabriz University of Medical Science (ethics code: 5/4/7617). The ethical considerations of the study were informed consent, voluntary participation, permission to record interviews and to observe students on wards and in college. Prior to the study, participants were informed verbally about the aim of the study and that they could withdraw from the study at any time. All participants provided written informed consent. To protect the privacy, confidentiality, and the identity of the participants, all identifying information was removed from the transcripts prior to analysis and only one researcher conducted the interviews.

\section{Results}

The demographic variables of the participants can be seen in Table 1. According to the aim of this study, we explored the factors influencing nursing students' self-esteem using a qualitative content analysis. Factors were assigned into two themes called "pressure factors" and "protective factors." It seems that interaction between the two themes just being like a seesaw and interaction between those two results in formation and level of self-esteem of nursing students.

In this study, the pressure factors which contained subthemes of low self-efficacy, sense of triviality, ineffective instructor-student interaction, and low self-confidence, and the protective factors with the subthemes knowledge acquisition, mirror of valuability, professional autonomy, religious beliefs, and choosing nursing with interest emerged and were located on the opposite sides of each other like the planes of a seesaw. In that sense, the interaction between the two

Table 1

Demographic variables of nursing students who participated in research.

\begin{tabular}{|c|c|c|c|}
\hline Variable & & $\mathrm{N}$ & $\%$ \\
\hline \multirow[t]{4}{*}{ Age } & $18-20$ & 1 & 6.25 \\
\hline & $22-24$ & 5 & 31.25 \\
\hline & $24-30$ & 8 & 50 \\
\hline & $30-35$ & 1 & 6.25 \\
\hline \multirow[t]{2}{*}{ Sex } & Male & 9 & 56.25 \\
\hline & Female & 7 & 43.75 \\
\hline \multirow[t]{3}{*}{ Previous work } & As a student work & 4 & 25 \\
\hline & Human resources plan & 2 & 12.5 \\
\hline & Only being as a student & 10 & 62.5 \\
\hline \multirow{4}{*}{ Semester } & $1-2$ & 1 & 6.25 \\
\hline & $5-6$ & 6 & 37.5 \\
\hline & $7-8$ & 7 & 43.75 \\
\hline & Graduated bachelor degree & 2 & 12.5 \\
\hline \multirow{2}{*}{$\begin{array}{l}\text { Times of } \\
\text { interview }\end{array}$} & 1 & 13 & 81.25 \\
\hline & 2 & 3 & 18.75 \\
\hline \multirow[t]{2}{*}{ University } & $\begin{array}{l}\text { Tabriz University of Medical Sciences (Tabriz and } \\
\text { Maragheh branch) }\end{array}$ & 13 & 81.25 \\
\hline & Islamic Azad university (Tabriz and Bonab branch) & 3 & 18.75 \\
\hline
\end{tabular}


themes appears to be instrumental in the formation and level of selfesteem in nursing students.

Pressure factors:

1: Low self-efficacy:Nursing students may have a generally low selfefficacy or, due to lack of adequate training or lack of support from their lecturers, may not have an adequate understanding of their self-efficiency. Both cases can eventually result in an experience of failure. By experiencing numerous failures and the increased stress of the probability of failure, gradually, their professional selfesteem will decrease. For example, one student said:

My classmate is a stressed person. I saw him enter the vein but tear the vein during vein puncture several times; this leads to a bad experience. This experience is repeated every time he attempts to perform vein puncture ... he was a stressful man ... If this problem continues... Well ... his self-esteem will decrease ... he will ask himself, "how he should be proud of being a nurse?"

2: A sense of triviality:A sense of triviality is considered to be negative pressure factor. Triviality can be related to lack of provision of the students' needs and facilities in the university or the clinic or the social acceptability (judgment of patients or family or people around him) of being a nurse. Most of the students believed that the [qualified] nurses greeted the medical students more pleasantly than the nursing students. With regard to patients' judgments, student B said:

When I educated a man about [the] complication [of] a drug ... patient said to me, "Are you a medical student?" ... No I am a nurse ... she said:, "You are a nurse?" . . . It's grateful . . . I am proud myself. . .

3: Ineffective instructor-student interaction:The instructor-student interaction is also explored as an important pressure factor. One student said:

The education environment and the professors are all great. .. But sometimes there is distance between the students and our professors. .. When we work with proficient professors in the clinic, I fell that I have a high level of self-esteem than others.

4: Low self-confidence:In the present study, it was found that students' self-confidence, especially if supported by their mentors, can lead to greater success. As a result, it can lead to students' feeling of selfworth as a nursing student. In this regard, a student said:

Some of my friends who work in the practice clinic are very certain and perform their duties whether right or wrong. Our mentors can then correct them and in time they are able to correct themselves. The self-confidence that they have strengthens their feeling of selfworth...

\section{Protective factors:}

1: Knowledge acquisition: Increasing knowledge is a strategy by which to deal with the lowering professional self-esteem of the students. A student declared:

I now feel that my self-esteem is better than the first and second semester, because my knowledge has increased. A nursing student can only justify her power or ability by her knowledge.

\section{Another student said:}

I tried to improve my knowledge and information, so that nobody could say that she is just a nursing student and does not know anything, and so that if there is a scientific discussion in the ward, I could be participate..."

2: Mirror of valuability:Instructors and employed nurses are considered a mirror when evaluating the valuability of the nursing profession for nursing students. The behavior, the function, and personality of the instructors have a great effect on students. If the instructor does not take part in clinical procedures with students, the student thinks that he/she does not consider this occupation as a valuable profession. According to the students, the ward staff are kind of a mirror showing their future, too.

One student stated:

I look at to my professors ... finally I could be as a nurse ... just like him... It is honorable.

3: Professional autonomy:Professional autonomy was important to the students in this study. If nursing students believed that nursing is an independent profession, then her|his self-esteem could be increased. Student C said:

Nursing process. ... When our instructors emphasized on it then, I had a good feeling ... It was special for my job. . .

4: Religious beliefs:According to the participants' experience, religious beliefs were powerful factors in the protection against pressure factors. As one student said:

It is an honor for me that nursing serves the people of the community.... Being a nursing student prepare[s] me an opportunity to serve to other people ... it is honorable for me.

5- Choosing nursing with interest:Being motivated to pursue nursing as a career was an important protective factor. The student in this next quotation pursued nursing for the wrong reasons and this has influenced her perception of it as a career:

I do not like myself as a nurse; I did not like this field in the first place. My mother's friend was a nurse and she always talked about nursing. My best friend also chose nursing in the university entrance examination. I chose it, too, so we could be together in the university. I do not believe that nursing is a professional or important career.

\section{Another student said:}

I chose this profession with $70 \%$ interest and $30 \%$ for its career market. I liked this profession. ... There were other disciplines that I could also choose, but I felt that I could be more successful in this field. I am proud that I am a nursing student.

\section{Discussion}

The concept of self-esteem sometimes is used to refer to a personality variable that represents the way people generally feel about themselves. Researchers call this form of self-esteem global self-esteem, but sometimes, it is used to describe the way people evaluate their various abilities and attributes. For example, a person who doubts his ability in school may be said to have low academic self-esteem (Kernis, 2013). Nursing students' self-esteem is a special aspect of the selfesteem concept, thus it seems that the role of influencing factors (such as efforts for professional autonomy, etc.) could be specific to the nursing discipline. The effect of general self-esteem on special aspects of selfesteem (such as academic self-esteem, athletic self-esteem, or nursing student's self-esteem) is not in doubt; however, we wanted to explore the factors influencing nursing students' self-esteem during education programs. Two themes which describe the negative pressure factors and the positive protective factors were explored in this regard. The findings of this study suggest that the interaction between the pressure and the protective factors operate similarly to a seesaw. When pressure factors are strong in educational systems, then nursing student selfesteem is diminished. Alternatively, if the protective factors are prevalent in educational systems, then the level of self-esteem increases in students. In that sense, nursing student's self-esteem can be in a state 
of flux depending of the educational climate that they are exposed to. Furthermore, factors that are constant such as the student's motivation to pursue nursing as a career may have a stabilizing effect in terms of providing balance to self-esteem levels. This could be described as a double-edged sword as these stabilizing factors can be both pressuring and protective. In addition, attempts at raising self-esteem in nursing students may be futile if factors such as "sense of triviality" and "choosing nursing with interest" are strong. While some of the pressure and protective factors can be manipulated to improve self-esteem, it is imperative that only those students that are motivated to pursue nursing as a career and who understand the nature of nursing are encouraged to enroll in nurse education programs. Those involved in the recruitment of nursing students need to present an honest but encouraging representation of nursing so that school-leavers and others thinking about a career in nursing can make an informed decision when applying. Furthermore, those nursing students who find that nursing is not to their liking need to be supported in their decision to pursue other educational alternatives. In this study, more than half of the participants are male; given that nursing has traditionally and consistently been cited as a female occupation, this figure is high. In Zamanzadeh et al.'s (2013) qualitative study exploring why men chose nursing in Iran, only three of the eighteen participants purposely chose nursing as a career (Zamanzadeh et al., 2013). It is likely that the men in this study are similar and this has negatively influenced their perceptions of esteem. Promoting nursing as a viable occupation for men may encourage more men to choose nursing although it will not detract from those who just want a university education or who wish to avoid military service. According to Johnson's Behavioral System Model, humans try to maintain their balance and effectively act through acceptance of and adaptation to environmental pressures with the help of acquired patterns (Memarian, 2011). Many of the pressure and protective factors cited by the students are outside their control in the sense that they are to do with the ward learning environment or faculty staff (for example, ineffective instructor-student interaction or mirror of valuability). Students engaged in nurse education programs who feel that clinical staff take an interest in them and who feel that staff on the ward or unit are approachable will respond to that learning environment positively and will report a positive learning experience (Dunn and Hansford, 1997). This is of utmost importance to students especially those who lack confidence in their abilities or who feel that they have a knowledge or skills deficit. Those instructors who take time with students and who take an active involvement in the students learning will positively influence the students learning and thus their self-esteem. Arguably, the social milieu of the learning environment of students is perceptive and responsive to changes in esteem. Wards where there is a negative impression of the role of nurses will negatively impact on the overall care that patients receive (Baraz et al., 2015). Fostering staff that are positive and engaged with student learning will both improve students esteem as well as improve the overall ward/department atmosphere. Furthermore, in students who find that they have chosen nursing for the "wrong" reasons, positive role models and engaging instructors may be able to tease out students caring abilities during clinical placements thereby arresting or decreasing attrition rates. While religious belief is cited here as a protective factor, caution should be taken when promoting nursing as a vocation as this may compete with nursing's pursuance of a professional identity and greater professional autonomy as a healthcare discipline.

\section{Conclusion}

Nurse educators and nursing faculties need to be aware of these factors and work toward creating learning environments that foster nursing as a professional, autonomous career. Furthermore, thought needs to be given to the recruitment of student nurses to avoid admitting students who enroll in nursing programs for insincere reasons, although it is acknowledged that this is challenging. A greater understanding of the relationship between protective and pressure factors is also required and strategies need to be designed to promote nursing as a career that is held in high esteem.

Nurse educators and nursing faculties not only should try to improve the students' skills and knowledge but should also try to enhance the self-esteem protective factors and decrease pressure factors by enhancing the nursing students' feeling of being important, using participatory teaching methods, considering students' feedback, and attempting to resolve complaints and improve facilities at the clinics are also recommended.

\section{Author Contribution}

LV, VZ designed of the study, FJT analyzed data, BK and RBG reviewed manuscript critically, AG and FGT drafted the article and FJT finally approved the manuscript.

\section{Acknowledgment}

This article was part of a PhD dissertation approved by the research deputy of Tabriz University of Medical Sciences with the ethics code 5/ 4/7617. Our sincere appreciation goes to the research deputy for their financial support and all the students who participated in this research.

\section{References}

Azizi, M., Khamseh, F., Rahimi, A., Barati, M., 2013. The relationship between self-esteem and depression in nursing students of a selected medical university in Tehran. J. Nurs. Educ. 1 (1), 28-34.

Baraz, S., Memarian, R., Vanaki, Z., 2015. Learning challenges of nursing students in clinical environments: a qualitative study in Iran. J. Educ. Health Promot. 4 (1), 52.

Barkhordary, M., Jalalmanesh, S., Mahmodi, M., 2009. The relationship between critical thinking disposition and self esteem in third and fourth year bachelor nursing students. Iran. J Med. Educ. 9 (1), 13-19.

Begley, C.M., White, P., 2003. Irish nursing students' changing self-esteem and fear of negative evaluation during their preregistration programme. J. Adv. Nurs. 42 (4), 390-401.

Cha, N., Sok, S., 2014. Depression, self-esteem and anger expression patterns of Korean nursing students. Int. Nurs. Rev. 61 (1), 109-115.

Dimitriadou-Panteka, A., Koukourikos, K., 2014. The concept of self-esteem in nursing education and its impact on professional behavior. Int. J. 7 (1), 6.

Dunn, S.V., Hansford, B., 1997. Undergraduate nursing students' perceptions of their clinical learning environment. J. Adv. Nurs. 25 (6), 1299-1306.

Furegato, A.R.F., Santos, J.L.F., Silva, E.C.d., 2008. Depression among nursing students associated to their self-esteem, health perception and interest in mental health. Rev. Lat. Am. Enfermagem 16 (2), 198-204.

Iacobucci, T.A., Daly, B.J., Lindell, D., Griffin, M.Q., 2013. Professional values, self-esteem, and ethical confidence of baccalaureate nursing students. Nurs. Ethics 20 (4), 479-490.

Janati, Y., Musavi, A., Azimi, H., Fani Saberi, L., Hamta, A., Feyzi, S., 2012. Investigating emotional intelligence and self esteem level among nursing and midwifery students of Mazandaran University of Medical Sciences in 2010. J. Mazandaran Univ. Med. Sci. 22 (1), 254-260.

Kamali, S., Jafari, E., Fathi, A., 2009. Correlation between academic achievement and selfesteem in students of Zanjan Faculty of Nursing and Midwifery 1388. J. Med. Educ. Dev. 2 (2), 17-24.

Kanning, U.P., Hill, A., 2012. Organization-based self-esteem scale-adaptation in an international context. J. Bus. Media Psychol. 3 (1), 13-21.

Kernis, M.H., 2013. Self-esteem issues and answers: a sourcebook of current perspectives. Psychology Press.

King, C.A., Naylor, M.W., Segal, H.G., Evans, T., Shain, B.N., 1993. Global self-worth, specific self-perceptions of competence, and depression in adolescents. J. Am. Acad. Child Adolesc. Psychiatry 32 (4), 745-752.

Lakdizaji, S., Abdollahzadeh, F., Hassankhanih, H., Kalantari, M., 2013. Impact of guided reciprocal peer questioning on nursing students' self-esteem and learning. Iran. J. Nurs. Midwifery Res. 18 (4), 285.

Lo, R., 2002. A longitudinal study of perceived level of stress, coping and self-esteem of undergraduate nursing students: an Australian case study. J. Adv. Nurs. 39 (2), 119-126.

Megahed, M.M., Mohammad, F.A., 2014. Effect of cooperative learning on undergraduate nursing students' self-esteem: a quasi-experimental study. J. Nurs. Educ. Pract. 4 (11), p1.

Memarian, R., 2011. Application of nursing concepts and theories. Tarbiat Modaress University Press.

Ni, C., Liu, X., Hua, Q., Lv, A., Wang, B., Yan, Y., 2010. Relationship between coping, selfesteem, individual factors and mental health among Chinese nursing students: a matched case-control study. Nurse Educ. Today 30 (4), 338-343. 
Ni, C., Lo, D., Liu, X., Ma, J., Xu, S., Li, L., 2012. Chinese female nursing students' coping strategies, self-esteem and related factors in different years of school. J. Nurs. Educ. Pract. 2 (4), p33.

Peterson-Graziose, V., Bryer, J., Nikolaidou, M., 2013. Self-esteem and self-efficacy as predictors of attrition in associate degree nursing students. J. Nurs. Educ. 52 (6), 351-354.

Peyrovi, H., Ghezelbash, S., Ghorbani, A., Inanloo, M., Alizadeh, H., Haghani, H., 2012. Relationship between self-esteem and demographic variables among undergraduate student nurses. J. Health Care 14 (4).

Rolfe, G., 2006. Validity, trustworthiness and rigour: quality and the idea of qualitative research. J. Adv. Nurs. 53 (3), 304-310.

Rosenberg, M., 1986. Conceiving the self.
Suliman, W.A., Halabi, J., 2007. Critical thinking, self-esteem, and state anxiety of nursing students. Nurse Educ. Today 27 (2), 162-168.

Tameh, A.I., Hosseinzadeh, M., Aghajari, P.E., 2014. Relationship between attachment style, self-esteem and hopefulness in nursing students. J. Zabol. Univ. Med. Sci. Health Serv. 6 (1), 16-25.

Yoon, H.S., Kim, G.-H., Kim, J., 2011. Effectiveness of an interpersonal relationship program on interpersonal relationships, self-esteem, and depression in nursing students. J. Korean Acad. Nurs. 41 (6), 805-813.

Zamanzadeh, V., Azadim, A., Valizadeh, L., Keogh, B., Monadi, M., Negarandeh, R., 2013. Choosing and remaining in nursing: Iranian male nurses' perspectives. Contemp. Nurse 45 (2), 220-227. 